\title{
PRINT-ON STRATEGIES TO BOND INJECTION MOLDED PARTS WITH STRUCTURES PRODUCED BY FUSED- DEPOSITION-MODELING
}

\author{
Richter, Alina (1); Kessing, David (2); Fischer, Fabian (1); Pelzer, Lukas (3); Dilger, Klaus (4) \\ 1: Volkswagen AG, Group Research; 2: Institute for Machine Elements and Systems Engineering, \\ RWTH Aachen University; 3: Institute of Plastics Processing, RWTH Aachen University; 4: Institute \\ of Joining and Welding Technology, Technical University Braunschweig
}

\begin{abstract}
The biggest advantage of Additive Manufacturing is the individualization of products. Mass Customization is well known as a promising future application. The use of Additive Manufacturing for assembly groups is mostly not reasonable, however combining it with conventional manufacturing processes can lead to new opportunities.

This paper works out concepts to join, by using similar material combinations, an injection molded part with an additive deposited geometry by the Fused-Deposition-Modeling (FDM) process. Therefore, two of the main industrially used polymers, acrylonitrile butadiene styrene (ABS) and polypropylene (PP), are selected for further study. In particular, this investigation focuses on the procedural potentials and surface preparation of the injection molded part. By the variation of adhesive bonding, the fusion of similar materials can be identified and tested in several series of testing.

First in general a direct joining function by the FLM process will be tested. After proving this hypothesis, the results will be summarised in a recommendation of joining similar materials, which are manufactured in different ways.
\end{abstract}

Keywords: 3D printing, Additive Manufacturing, Process modelling

Contact:

Richter, Alina

Volkswagen AG

Volkswagen Group Research

Germany

alina.richter@volkswagen.de

Cite this article: Richter, A., Kessing, D., Fischer, F., Pelzer, L., Dilger, K. (2019) 'Print-On Strategies to Bond Injection Molded Parts with Structures Produced by Fused-Deposition-Modeling', in Proceedings of the 22nd International Conference on Engineering Design (ICED19), Delft, The Netherlands, 5-8 August 2019. DOI:10.1017/dsi.2019.86 


\section{INTRODUCTION}

Additive Manufacturing is compared to conventional processes a relatively young technology, which is gaining more and more attention because of its toolless layer-by-layer methods (Lachmayer et al., 2016). Additive Manufacturing provides more variation and individualization of products because of its characteristics. (Feldhusen and Grote, 2013) This creates a foundation for Mass Customization Lachmayer et al., 2016), which allows manufacturer to produce low amounts of highly individualised products without an economic disadvantage. Based on this Additive Manufacturing can initiate a new industrial revolution as soon as it is compatible with conventional production process (Berman, 2012). Within the scope of this paper the combination of conventional and Additive Manufacturing processes is part of the investigation, focusing on the individualization of injection molded parts by a direct print-on strategy with the FDM process. At this point the added structure will be investigated and accumulated results will help to optimize a best practice strategy to join components by the FDM process and get more variety. The motivation for this research is the reduction of tool costs. Therefore, producing structural components in unit forms by injection molding and then individualize them with Additive Manufacturing could be a solution. With the help of Additive Manufacturing basic equipment and components can be customized in an easy and adaptable way. For a new and innovative way of production, it is necessary to use the advantages of both manufacturing processes. The present paper will explore the possibilities of joining acrylonitrile butadiene styrene (ABS) and polypropylene (PP) to a plane injection molded plate via FDM process. In doing so, the bonding of similar type polymers, ABS - ABS and PP - PP, will be verified. The created bonding should be permanent. In concluding, the results will be presented as guidance for printing-on injection molded parts.

\section{BACKGROUND}

The term Additive Manufacturing describes a process which produces parts by extruding small strings of molten material to form layers. The material hardens immediately after being extruded form the nozzle and creates iterative three-dimensional objects (Feldmann and Gori, 2017). Based on a digital model, Additive Manufacturing extrudes or coats material in x-y-layers and repeats this process in zdirection to create a solid body (Feldmann and Pumpe, 2016), (Lachmayer et al., 2016).

The Fused-Deposition-Modeling is the most common Additive Manufacturing process (Gibson et al., 2015). It uses a heated nozzle to extrude the filament layer by layer (Badiru and Valencia, 2017). To plasticize the polymer energy is brought into the material. After cooling down a permanent bonding between the extruded strings is established (Gebhardt and Hötter, 2016). The main components for the FDM are a hotend with nozzle, stepper motor, build plate and a kinematic movement in $\mathrm{x}-\mathrm{y}-\mathrm{z}-$ direction. Figure 1 gives an overview about all main components.

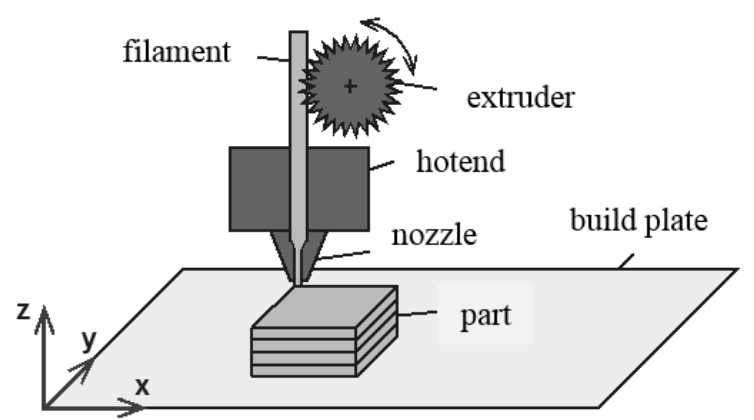

Figure 1. Main components of the FDM process

\section{Acrylonitrile butadiene styrene}

During this investigation, a very pure acrylonitrile butadiene styrene (ABS) filament will be used. This prevents the material from having internal tensions and unpleasant impacts during the printing. This ensures to have the results not distorted by any additives in the material, to be able to make general statements about additive manufacturing with $\mathrm{ABS}$ and to record all forces, which occur on the bonding areas. A nozzle temperature is recommended between $220{ }^{\circ} \mathrm{C}$ and $270{ }^{\circ} \mathrm{C}$. The heated build plate is set about $90{ }^{\circ} \mathrm{C}$ till $110^{\circ} \mathrm{C}$. The base material of ABS injection molded plates is made by the 
company Ineos Styrolution for all print-on tests. All printing parameters in detail are included in the appendix, table 1 . The extrusion temperature during injection molding process is about $250{ }^{\circ} \mathrm{C}$. The surface and dimensions are $95.5 \mathrm{~mm}$ x $95.5 \mathrm{~mm}$ by a thickness of $2.15 \mathrm{~mm}$.

\section{Polypropylene}

In this paper, the polypropylene (PP) filament from the company Verbatim is used in sizes of $1.75 \mathrm{~mm}$ and $2.85 \mathrm{~mm}$. Based on the studies of (Kuznetsov et al., 2018) and (Wittbrodt and Pearce, 2015), the addition of color particles can have a negative impact to the strength of materials, so only uncolored filament is used. Verbatim recommends a nozzle temperature between $200{ }^{\circ} \mathrm{C}$ and $240{ }^{\circ} \mathrm{C}$. The heated build plate is set to about $80{ }^{\circ} \mathrm{C}$ and the maximum printing speed is $30 \mathrm{~mm}$ per second. All printing parameters in detail are included in the appendix, table 1 . The base material of PP injection molded plates is made by the company Borealis AG for all print-on tests. This material is $20 \%$ fiber glass and $10 \%$ mineral reinforced. The extrusion temperature during injection molding process is about $230{ }^{\circ} \mathrm{C}$. The surface is $95.5 \mathrm{~mm}$ x $95.5 \mathrm{~mm}$ by a thickness of $1.9 \mathrm{~mm}$.

\section{THEORETICAL APPROACH}

The research assignment shall offer options and selections of printing parameter, by using appropriate methods for a successful print-on process with FDM in combination with injection molded parts for individualization. At this point, the bonding between similar plastics should be able to absorb high forces and, at the same time, not get separated in a non-destructive way.

\section{Preliminary test}

At first, it has to be proved that in general a bonding between similar materials is possible. With the help of a simple test setup, where an injection molded base part is mounted on the build plate in a known position. After that, a simple test object, a cuboid, is loaded into the slicing software and centered onto the injection molded part in $\mathrm{x}$ - and $\mathrm{y}$ - direction. In z-direction, the object is elevated by the thickness of the injection molded part, so it looks like it is floating in the air, see figure 2 (a). Because of this, the support structure needs to be deactivated in the slicing software. After starting the printing job, the nozzle begins printing right on the surface of the injection molded part. After being finished, the result is a bonding between plate and cuboid, see figure 2 (b) and (c) with each material combination.

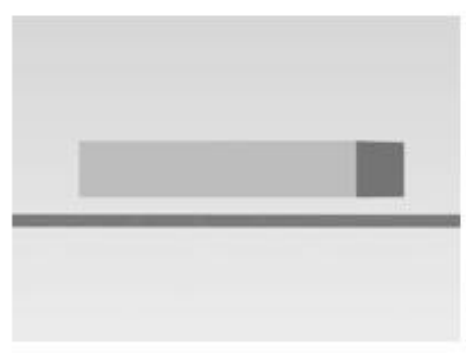

(a) Positioning of cuboid considering the height of the injection molded plate

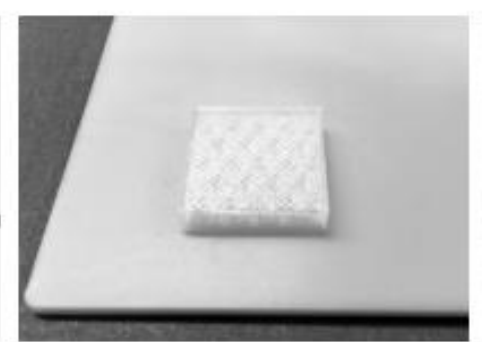

(b) Print-on cuboid made of $P P$

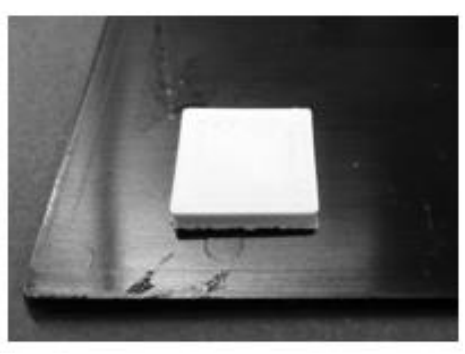

(c) Print-on cuboid made of $A B S$

Figure 2. Experiments for substance-to-substance bond of similar materials

Therefore, the preliminary test revealed that similar materials can have an adhesive bonding with an injection molded part. Based on this conclusion, no constructive actions or design features are necessary to reach a bonding for PP-PP or ABS-ABS. The strength of the bonding can still be increased, based on the principles of plastic welding.

\subsection{Modification surface}

For the injection molding process additives like release agents for demolding are always necessary. The release agents avoid clogging and help to eject parts from the tool shape (Rosato, 2000). This prevents adhesion between tool and finished part while remaining particles of the release agents can be found on the surface, which can have an impact on the purpose of bonding these parts. First, preprocessing strategies of the surface will be investigated in regard to find the maximum strength between injection molded part and the print-on structure made by FDM. In order to ensure 
comparability of the data and processes, a non-pre-processed surface and its print-on structure will serve as reference. In the second step, the injection molded plate will be cleaned by a cleaning agent. Furthermore, the surface can be pre-processed by sandpaper to enlarge the surface slightly, which can have a positive effect on the bonding strength.

At last, based on plastic welding process, the surface temperature of the injection molded plate can be increased so that both materials get into the molten state for better adhesion and connection of their polymer chains. The above-mentioned print-on process is related to hot gas welding by extrusion of filler material, with the difference that both welding parts get heated-up. To achieve the best possible bonding, an investigation of the procedure is necessary.

\subsection{Modification print parameters}

Beside pre-processing the surface of the injection molded part, another optimization method to increase the adhesion is the variation of the print parameters for the first printed layer. For example, pre-heating the surface of the injection molded part with the preheated nozzle. Since this step can be established via the slicing-software and does not need an extra step, it is counted as a print parameter and not as a surface pre-process. For this purpose, the heated nozzle is dipped into the injection molded part by several millimeters, without extruding any material. A special pattern is brought into the part, resulting in an increased and heated surface. Both these factors should lead to a better bonding.

\subsection{Modification of standards}

When choosing the test method, the focus is to stress to the bonding by peeling it. Comparing the applied load, a tensile test stresses the whole bonding surface at once, whereat a peeling test only stresses a line contact. Whenever one line contact breaks down, the next one is stressed. Since the applied forces are not distributed over the whole bonding surface, this method represents the most critical condition.

Especially within the field of additive manufacturing, the standardization of test methods is difficult since apparently the same parts can have different process and material parameters. Because of that, there are no explicit standards for mechanical test of additive manufactured parts up to now (Richard et al., 2017). Standards of otherwise produced components can only be used partially because of the anisotropic characteristics caused by the layer-by-layer structure (Chua et al., 2017). Additionally, the by these standards defined geometry of the test pieces cannot be used. The DIN EN 12814 provides a test for welded connections of thermoplastic parts and, for this reason, describes the most obvious standard to be used here. Part 4 of this standard describes the peel test. (DIN EN 12814-4, 2017) Figure 3 is shown the new modification of geometry as well as force transmission into to the specimen. The specified testing speed plus required number of specimens are according to the norm.

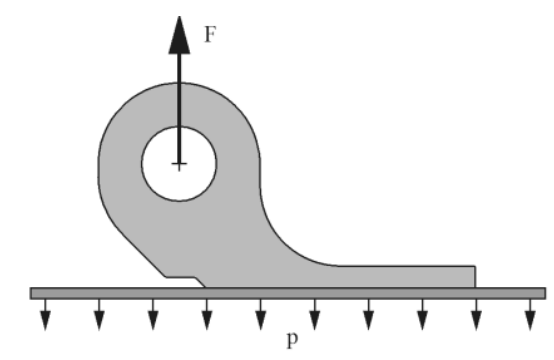

Figure 3. Geometry of modified specimen in accordance with DIN EN 12814-4

\section{EXPERIMENTAL RESULTS AND INTERPRETATIONS OF NEW PRINT-ON STRATEGIES}

To improve the quality of the print, the print parameters for each filament were optimized and can be seen in appendix 1 . When printing-on with similar materials, all presented print-on strategies can be used with either the Ultimaker 2 or the Felix Pro 1 (see figure 4). Therefore, a comparison of both machines is possible. Based on the first procedure, where non pre-processed injection molded plates without any modifications are printed-on. For that matter, six samples are made, to ensure significant reference values. The additional procedures for printing-on similar materials will be done two times on 
every unit, so a trend regarding the adhesion of the bonding can be identified. The following preprocesses will be investigated (see figure 4).

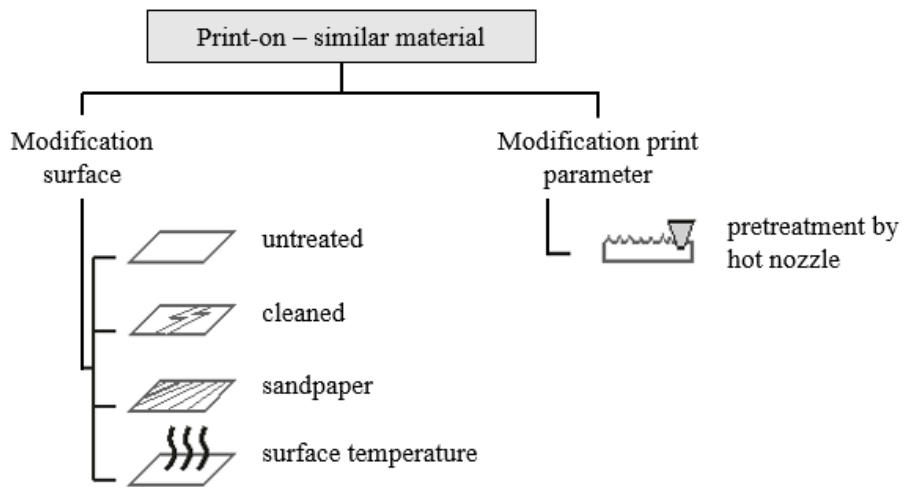

Figure 4. Entire solution space for similar materials

\section{PP - PP}

Figure 5 shows the results for the bonding of PP - PP. Represented in a box-plot to not only show the average values of the maximum forces, but also present the variation between samples, which are made with the same process. Because of additional variations between both 3D printers, the values are not only separated by procedure, but also by printer.

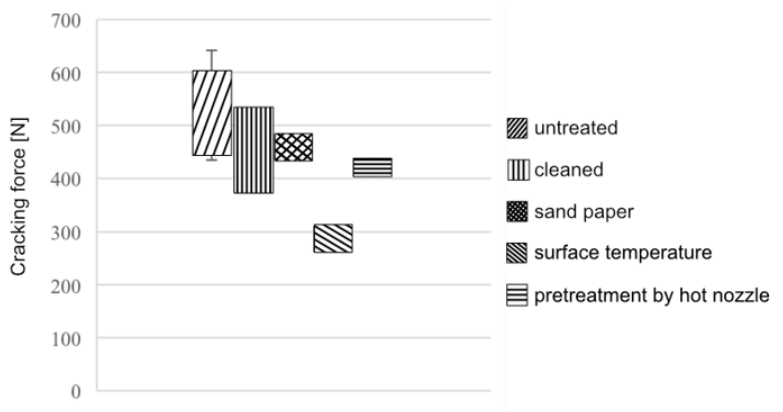

(a) Measurements of specimens made of Ultimaker 2

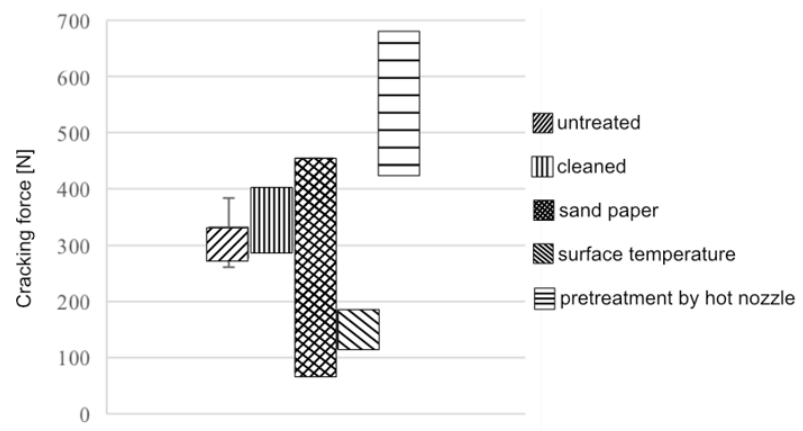

(b) Measurements of specimens made of Felix Pro 1

Figure 5. Box-Plots of bonding PP - PP

With samples made by the Ultimaker 2, the printing-on untreated injection molded parts had the best results in regard to bonding. The average value of the maximum forces is $516.93 \mathrm{~N}$. In exception of the variating the surface temperature, all test results had very little variation. In addition, within the several procedures test results showed only little variation.

In contrast, the samples, produced by the Felix Pro 1, did not lead to a definite statement. On the one hand, major variations are identified within the individual procedures and on the other hand, the differences between the individual procedures are very high. For example, the smallest measured value is $73.52 \mathrm{~N}$ (sandpaper), the greatest at $675.59 \mathrm{~N}$ (pretreatment by hot nozzle). Since the G-code for all test samples is based on the same STL-File, uses the same print parameters and the same filament from one supplier was used for printing on both machines, such huge differences between both machines were not expected. To get to the source of that, differences between the 3D printers will be investigated.

First obvious difference is the mechanics. While the Ultimaker 2 moves the print head in $\mathrm{x}$ - and $\mathrm{y}$-axis and the build plate in z-direction, moves the Felix Pro 1 the print head only in $\mathrm{x}$-direction and the build plate in y-and z-direction. Both machines have a much higher resolution in mechanical movements than necessary for the FDM process. This can be verified, since printed parts of both machines cannot be distinguished optically. Looking at the extrusion process, the difference is that the Ultimaker 2 uses $2.85 \mathrm{~mm}$ filament and the Felix Pro $11.75 \mathrm{~mm}$. This has an effect on the amount of applied energy to plasticize the material and on the maximum possible precision respectively the maximum volume of the extrusion. However, as the produced samples are neither close to the maximum precision nor are they printed very fast, these differences cannot explain the problem. It can also not clarify the 
variations within the Felix Pro 1 printed samples. In addition, the difference of applied energy to plasticize the material can also not be the cause for the differences, since the melting zones are determined by the filament manufacturer. This means a reliable extrusion is guaranteed with both printers. It is possible, that the in the G-code defined hotend temperature is not reached on one or both machines. This, for example, could be caused by a bad calibrated temperature sensor inside the hotend, which is used for the temperature control while printing.

Another difference between both units, which is known for impacting the quality of a printed part, is the cooling of the print. Since this feature was deactivated on both units, it will not be investigated. The last big difference is the build plate levelling procedure. On the Ultimaker 2, this is done manually by hand. Three screws have to be adjusted to level the build plate in a perfect distance to the print head. However, the Felix Pro 1 printer has an automatic alignment procedure, which is using a combination of a hall-effect-sensor and step-motors. The hall-effect-sensor is also used for finding the z0-Postion when beginning a new print. During the investigation, the used sensor was not working reliable. In circa $50 \%$ of the tests, the sensor triggers to early which has the effect that the print does not start on the build plate or on the injection molded part, but in the air. This leads to the result, that the automatic build plate levelling does not work when using an unreliable hall-effect-sensor. Measuring the distance between nozzle and build plate via a thickness gauge showed that not only the distance between build plate and nozzle is wrong, also all four corners showed different distances. For example, gaps up to $0.4 \mathrm{~mm}$ were measured, which equates to 4 times the nominal value of $0.1 \mathrm{~mm}$. That means, the whole first layer, with a width of $0.2 \mathrm{~mm}$, of the printed structure has no contact to the injection molded part (see figure 6 (b)).

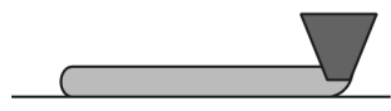

(a) Extrusion of first layer with correct distance between nozzle and build plate

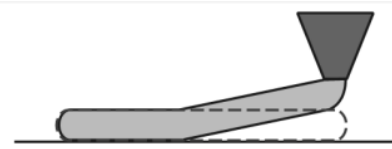

(b) Extrusion of first layer with incorrect distance between nozzle and build plate

Figure 6. Comparison between target distance and actual distance illustrated of Felix Pro 1

The poor reproducibility of the build plate levelling on the Felix Pro 1 shows that the distance between the first printed layer to the injection molded plate can have a major impact on the bonding between both. On the other hand, this could explain the huge differences between samples produced on this printer. Since a manually calibration is not possible on this machine, this hypothesis will be investigated on the Ultimaker 2. Therefore, distances of $0.4 \mathrm{~mm}, 0.3 \mathrm{~mm}, 0.2 \mathrm{~mm}$ and $0.0 \mathrm{~mm}$ will be tested. For every case, two samples are produced and tested regarding their bonding strength. Since the first series of tests was made with a distance of $0.1 \mathrm{~mm}$, the results of these tests will be used for the following comparison (see figure 7).

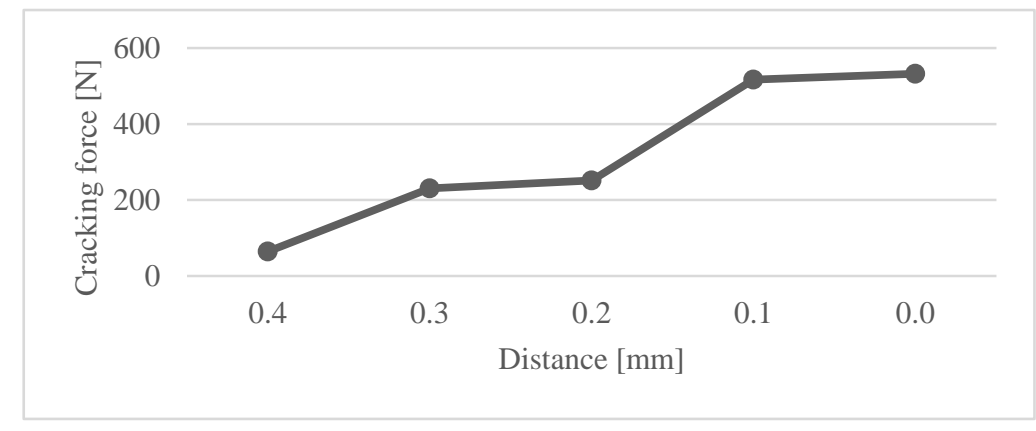

Figure 7. Cracking forces with different distances between nozzle and injection molded plate

It is becoming clear that the distance between base and print body has a major impact to the bonding strength. The average value for $0.4 \mathrm{~mm}$ is at $64.52 \mathrm{~N}$, in comparison to that it is $532.61 \mathrm{~N}$ at $0.0 \mathrm{~mm}$. However, the lack of distance between nozzle and base body give the extruded material no room to expand which can lead to failures in the printing process (see figure 8 (a)). Marking the filament before the extruder motor can illustrate that (see figure 8 (b)). It shows, that not enough filament was processed through the nozzle when the distance set to $0.0 \mathrm{~mm}$. But, since the injection molded plate is slightly touched by the nozzle, this procedure correlates with pre-treatment by hot nozzle. 


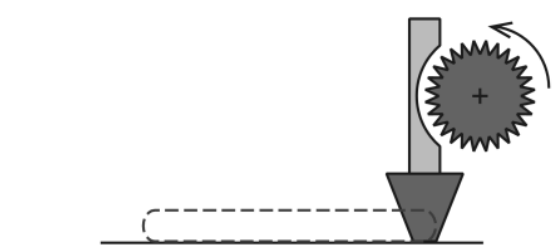

(a) Distance of $0.0 \mathrm{~mm}$

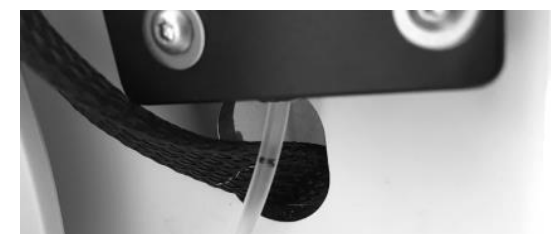

(b) Colored marking of filament

Figure 8. Risk of blockage with a distance of $0.0 \mathrm{~mm}$ between nozzle and injection molded plate

Because of the only minimal increased bonding strength in comparison to the $0.1 \mathrm{~mm}$ samples and the increased chance of breaking the samples, caused by the material extrusion problem, $0.1 \mathrm{~mm}$ can be confirmed as the standard parameter. These results not only explain the bad bonding strength on samples printed with the Felix Pro 1, but also the effect the bad reproducibility of the build plate levelling had. In addition, it shows why this printer had the best results with pretreatment by the hot nozzle, since within this procedure the first layer was printed $0.2 \mathrm{~mm}$ lower than standard, which compensates for the bad auto-levelling. Thereby, that can be compared to untreated surface, because the lowering of the print head of around $0.2 \mathrm{~mm}$ compensates the bad auto-levelling. Comparing the values of untreated surface, printed on the Ultimaker 2 and procedure pre-treatment by hot nozzle, printed on the Felix Pro 1, supports this theory (see figure 9).

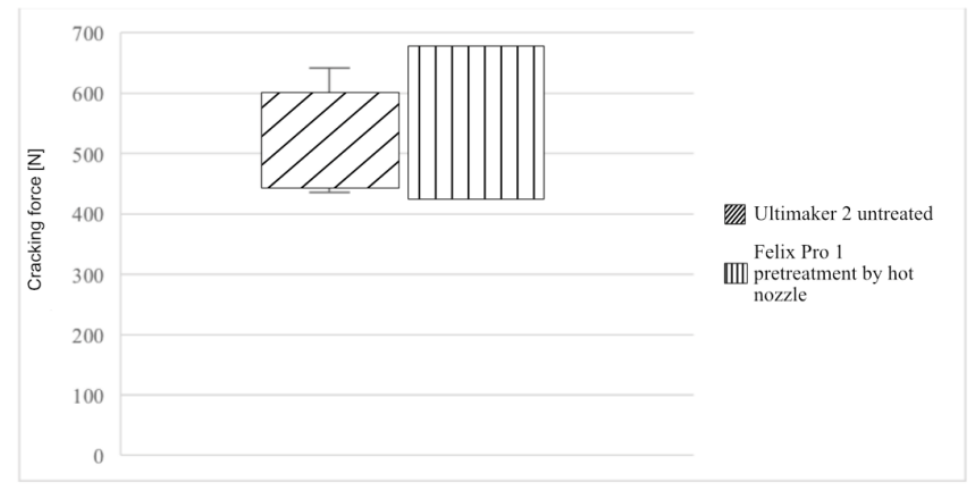

Figure 9. Comparison of forces between method 1 (no pre-processing) made by Ultimaker 2 and method 2 (nozzle-pre-processing) made by Felix Pro 1

Considering the point of breaking of the specimens, it becomes clear that all specimens broke at the joint, which includes all different procedures and distances between build plate and nozzle. Only with a distance of $0.0 \mathrm{~mm}$, a breaking can be identified at both, joint and base body. Since the highest values were measured with these samples, this leads to the conclusion that the bonding strength is equal to the strength between layers in a 3D printed part. That means, increasing the bonding strength is not necessary, since the strength of the print-on structure is already reached.

In Summary, the distance between nozzle and injection molded plate has the biggest impact to the bonding strength between both parts. The nozzle should be aligned to the base body as close as possible, without touching it. The standard value of $0.1 \mathrm{~mm}$ showed very promising results. Preprocessing the surface did not lead to a better bonding. However, pre-heating the injection molded plate keeps it from deforming while being in a print process.

\section{ABS - ABS}

The specimens, which are an ABS printed structure bonded on an ABS injection molded plate, broke down inside the structure and not at the bonded area. It shows that the strength of the bonding is higher than the layer-by-layer adhesion within the FDM part itself. For this reason, further studies of bonding area are not necessary, so no further pre-processes will be investigated. Figure 10 shows in a box-plot diagram all results of the bonding of ABS - ABS without surface modification printed by Ultimaker 2 (left) and Felix Pro 1 (right). 


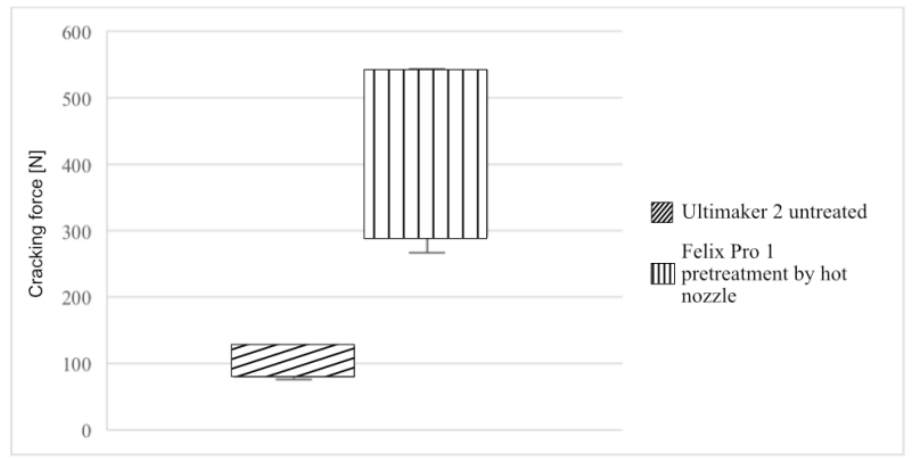

Figure 10. Box-Plots of bonding ABS - ABS

The reasons for substrate failure are imperfections during the printing process and interlayer tensions. Sometimes, the warping-effect can have a negative impact on the performance. Obvious cracks are repaired by soldering iron. The interlayer adhesion of the entire part might not be as high as supposed. That leads back to known problems with processing ABS in 3D-prints. This was also presented by (Tymrak et al., 2014), who says that the tensile strength of an additive manufactured specimen is always lower than the strength of the injection molded part. In comparison (Kuznetsov et al., 2018) shows that similar tensile strength is measured with PLA specimens made by injection molding and additive manufacturing. He also says that printed ABS parts delaminate even by low external forces. Delamination between layers occurs frequently, even during the printing process. He says, PLA parts have greater strength then ABS parts made by FDM, even though the material data sheets indicate the opposite. Figure 11 shows two ABS specimens with substrate failure underneath repaired cracks.

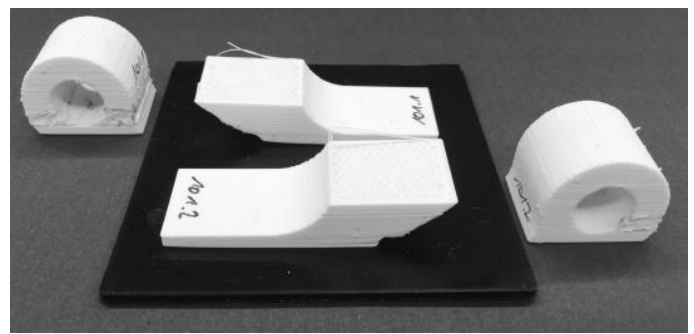

Figure 11. Substrate facture of $A B S$ specimens

All samples, made by the Felix Pro 1, had less cracks and faults, than the Ultimaker 2, which explains the better test results. The average measured force on the Felix Pro 1 is $420.32 \mathrm{~N}$. The reason for the higher interlayer adhesion should be investigated further. Since the average on the Ultimaker 2 is $100.1 \mathrm{~N}$ and to make sure the filament manufacturer is not the reason for that, a second filament manufacturer, innofil3D, is used to repeat the same tests. During that, the average strength went up to $378.8 \mathrm{~N}$. Nevertheless, all specimens did not show adhesion failure but substrate failure, see figure 12 (b).

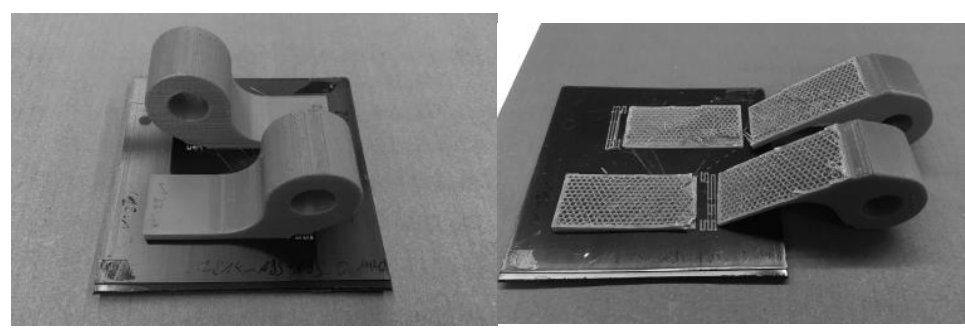

(a) Before testing

(b) After testing

Figure 12. Specimen made of ABS (Company Innofil3D)

To sum up, printing $\mathrm{ABS}$ on these 3D printers does not lead to a high interlayer bonding, despite optimizing parameters and using different filaments. Since no specimen broke at the bonding area, the bonding itself can handle more than $543.5 \mathrm{~N}$, which correlates with the highest measured strength of a specimen. This corresponds with the results of the PP - PP bonding. In principle, results for the printon strategy with similar material cannot be reproduced between different printers. 


\section{CONCLUSION}

This work looks at two material combinations, $\mathrm{PP}-\mathrm{PP}$ and $\mathrm{ABS}-\mathrm{ABS}$, one describing the injection molding material, the second one the filament. For PP - PP two 3D printers with different bedlevelling technologies were used. This effects the distance between nozzle and injection molded part in the first layer, which is a major factor to the bonding quality. The Ultimaker 2 uses a manual levelling by screws. In this case, the print-on strategy without any pre-processing had the best results because of a directly adhesive bond. In case of the Felix Pro 1 with its unreliable automatic levelling, a pre-treatment by the hot nozzle on the injection molded surface is helpful, as it roughens the surface for printing-on and counteracts to the inconstant distance. Further steps of pre-processing have no positive influence to the bonding and are not recommended.

With an adhesive bond at an ABS -ABS sample, the interlayer adhesion is weaker than the bonding itself. The aim of this paper was to individualize conventional manufactured parts by injection molding with the help of additive manufacturing. Based on known plastic joining techniques, methods for materials of the same type were designed, with which both parts are joined to an adhesive bond. These methods are organized with the help of a solution space, see figure 4 . Because of a lack of existing standardized test methods for additive manufacturing and, in addition, for print-on strategies and enlargements of conventional parts, the modification of the established peel test of DIN EN 12814-4 and of the specimen geometry was necessary, see figure 3. Finally, the samples for the developed methods were manufactured by the FDM 3D printer Ultimaker 2 and Felix Pro1.

The investigation of the PP - PP connection revealed that neither the pre-processing of the surface nor the customization of the parameters improved the bonding strength. Comparing the used 3D printer showed a measurable difference in bonding strength. After exploring that, this was caused by different nozzle to injection molded part distances. At further investigations, by varying this distance, a major impact to the bonding strength was revealed. Additionally, the tests showed that the adhesive bond and the interlayer bond of the printed part have the same maximum strength. The PP - PP combination can be printed-on without any pre-treatment and no additional optimization is necessary.

On the contrary, the investigation of ABS - ABS connection indicated that this plastic, due to its characteristics, cannot optimally be printed with the selected 3D printer. All tested specimens had a substrate failure and the bonding area remained intact. This means, there are no pre-treatments or additional optimizations needed regarding the improvement of the bonding, however an optimization of FDM with ABS is necessary.

Ultimately, future task for the individualization of conventional components have to be named, which hook up with the method described in this paper on bonding base bodies with 3D-printed-on parts. In this paper, the investigation focused on plane parts, but finally there should be print-on strategies for freeform components and their individualization. It needs to overcome the layer-by-layer limitation of 3D printers and to develop new methods for tool path planning for FDM.

\section{REFERENCES}

Berman, B. (2012), “3-D printing: The new industrial revolution”, Business Horizons, Vol. 55 No. 2, pp. 155162. http://doi.org/10.1016/j.bushor.2011.11.003.

Badiru, A. B. and Valencia, V. V. (2017), Additive Manufacturing Handbook, Product Development for the Defense Industry, CRC Press, Milton, http://doi.org/10.1201/9781315119106-3

Chen, X.A., Coros, S., Mankoff, J., Hudson, S.E., Encore, C., Hartmann, B. and Grossman, T. (2015), The 28th Annual ACM Symposium, Republic of Korea, Daegu, Kyungpook, pp. 73-82, http://doi.org/10.1145/2807442.2807507

Chua, C. K., Wong, C. H. and Yeong, W. Y. (2017), Standards, Quality Control, and Measurement Sciences in $3 D$ Printing and Additive Manufacturing, Academic Press is an imprint of Elsevier, United Kingdom, London, http://doi.org/10.18063/IJB.2017.02.009

DIN EN 12814-4:2017-02 (2017), Testing of Welded Joints of Thermoplastics Semi-Finished Products - Part 4: Peel Test, Norm, DIN Deutsches Institut für Normung e.V., Beuth Verlag GmbH, Berlin

Feldhusen, J. and Grote, K.-H. (2013), Pahl/Beitz Konstruktionslehre, Methoden und Anwendung Erfolgreicher Produktentwicklung, Springer Vieweg, Berlin, Heidelberg, Vol. 8., http://doi.org/10.1007/978-3-64229569-0

Feldmann, C. and Gorj, A. (2017), 3D-Druck und Lean Production, Schlanke Produktionssysteme mit Additiver Fertigung, Springer Gabler, Wiesbaden, http://doi.org/10.1007/978-3-658-18408-7.

Feldmann, C. and Pumpe, A. (2016), 3D-Druck - Verfahrensauswahl und Wirtschaftlichkeit, Springer Gabler, Wiesbaden, http://doi.org/10.1007/978-3-658-15196-6 
Gebhardt, A. and Hötter, J.-S. (2016), Additive Manufacturing, 3D Printing for Prototyping and Manufacturing, Munich, Hanser Publishers, Hanser Publications, Cincinnati, http://doi.org/10.3139/9781569905838

Gibson, I., Rosen, D. and Stucker, B. (2015), Additive Manufacturing Technologies, 3D Printing, Rapid Prototyping and Direct Digital Manufacturing, Springer, New York, Heidelberg, Dodrecht, London, Second Edition, 2015, http://doi.org/10.1007/978-1-4939-2113-3

Kuznetsov, V., Solonin, A., Urzhumtsev, O., Schilling, R. and Tavitov, A. (2018), "Strength of PLA components fabricated with fused deposition technology using a desktop 3D printer as a function of geometrical parameters of the process", Polymers, Vol. 10 No. 3, p. 313, http://doi.org/10.3390/polym10030313

Lachmayer, R., Lippert, R. B. and Fahlbusch, T. (2016), 3D-Druck Beleuchtet, Additive Manufacturing auf dem Weg in Die Anwendung, Springer Vieweg, Berlin, Heidelberg, http://doi.org/10.1007/978-3-662-49056-3

Rosato, D. V. (2000), Injection Molding Handbook, Kluwer Academic, Boston, Vol. 3, 2000, http://doi.org/10.1007/978-1-4615-4597-2

Richard, H. A., Schramm, B. and Zipsner, T. (2017), Additive Fertigung von Bauteilen und Strukturen, Springer Vieweg, Wiesbaden, http://doi.org/10.1007/978-3-658-17780-5

Tymrak, B. M., Kreiger, M. and Pearce, J. M. (2014), "Mechanical properties of components fabricated with open-source 3-D printers under realistic environmental conditions", Materials \& Design, Vol. 58, pp. 242246, http://doi.org/10.1016/j.matdes.2014.02.038

Wittbrodt, B. and Pearce, J. M. (2015), "The effects of PLA color on material properties of 3-D printed components", Additive Manufacturing, Vol. 8, pp. 110-116, http://doi.org/10.1016/j.addma.2015.09.006

\section{APPENDIX}

\begin{tabular}{|c|c|c|c|c|}
\hline $\begin{array}{l}\text { Material } \\
\text { Manufacturer }\end{array}$ & \multicolumn{2}{|l|}{$\begin{array}{l}\text { PP } \\
\text { Verbatim }\end{array}$} & \multicolumn{2}{|l|}{$\begin{array}{l}\text { ABS } \\
\text { Formfutura }\end{array}$} \\
\hline Diameter & $1.75 \mathrm{~mm}$ & $2.85 \mathrm{~mm}$ & $1.75 \mathrm{~mm}$ & $2.85 \mathrm{~mm}$ \\
\hline $3 \mathrm{D}$ printer & Felix Pro 1 & Ultimaker 2 & Felix Pro 1 & Ultimaker 2 \\
\hline Nozzle diameter & $0.4 \mathrm{~mm}$ & & $0.4 \mathrm{~mm}$ & \\
\hline Temperature hotend & $195^{\circ} \mathrm{C}-230{ }^{\circ} \mathrm{C}$ & $210^{\circ} \mathrm{C}-240^{\circ} \mathrm{C}$ & $220^{\circ} \mathrm{C}-260^{\circ} \mathrm{C}$ & $230{ }^{\circ} \mathrm{C}-270{ }^{\circ} \mathrm{C}$ \\
\hline Temperature build plate & 0 & & 100 & \\
\hline $\begin{array}{l}\text { Additional material on } \\
\text { build plate }\end{array}$ & tape & & glue stick & \\
\hline Extrusion multiplier & 1 & & 1 & \\
\hline Retraction distance & $1 \mathrm{~mm}$ & $6 \mathrm{~mm}$ & $1 \mathrm{~mm}$ & $6 \mathrm{~mm}$ \\
\hline Retraction speed & $30 \mathrm{~mm} / \mathrm{s}$ & & $60 \mathrm{~mm} / \mathrm{s}$ & \\
\hline Cooling & $\begin{array}{l}\text { For good geometr } \\
\text { from 2nd layer } \\
\text { For good tensile s }\end{array}$ & $\begin{array}{l}\text { ic accuracy: } 100 \% \\
\text { rength: } 0 \%\end{array}$ & $0 \%$ & \\
\hline Print speed & $40 \mathrm{~mm} / \mathrm{s}$ & $30 \mathrm{~mm} / \mathrm{s}$ & $50 \mathrm{~mm} / \mathrm{s}$ & \\
\hline Speed outer perimeter & $20 \mathrm{~mm} / \mathrm{s}$ & $15 \mathrm{~mm} / \mathrm{s}$ & $25 \mathrm{~mm} / \mathrm{s}$ & \\
\hline $\begin{array}{l}\text { Speed top and bottom } \\
\text { solid layer }\end{array}$ & $32 \mathrm{~mm} / \mathrm{s}$ & $24 \mathrm{~mm} / \mathrm{s}$ & $40 \mathrm{~mm} / \mathrm{s}$ & \\
\hline Other & - & & Closed chamber & \\
\hline
\end{tabular}

